\title{
Air pollution management in Rayong's industrial area, Thailand
}

\author{
C. Poboon, W. Jongjaiphakdee \& T. Singkham \\ National Institute of Development Administration (NIDA), Bangkok, \\ Thailand
}

\begin{abstract}
Rayong Province is the largest industrial area in Thailand, in which petrochemical and related productions are key industries. The area has been facing several severe environmental problems which have imposed serious impacts on the health and quality of life of the local people. The most important pollution in Rayong's industrial area is air pollution and the major air pollutants are VOCs, $\mathrm{SO}_{2}$, and $\mathrm{NO}_{\mathrm{x}}$. Several relevant government agencies have been trying to mitigate the problems through several measures mainly under the Rayong's Pollution Reduction and Mitigation Action Plan, nevertheless, the problems still exist. Hence, the objectives of this study are to study air pollution situation in the Rayong's industrial area, to examine the management of air pollution in the area, and to suggest ways for improvement of the management. The modified Balanced Scorecard (BSC) technique was employed for analysis of the management. Data were collected both from secondary sources and primary sources which are factories in the area using questionnaires. The study found that the average VOCs levels exceeded the standards in several areas while the average $\mathrm{SO}_{2}$ and $\mathrm{NO}_{\mathrm{x}}$ levels were still well lower than the standards. The evaluation of the air pollution management revealed that: 1) Effectiveness perspective, about $80-90 \%$ of the factories reported that they had better controls over leaking and emissions of $\mathrm{VOCs}_{\mathrm{SO}_{2}}$, and $\mathrm{NO}_{x}$; 2) Stakeholder perspective, most of the factories received supports and co-operations from central government agencies, other factories and local communities but not NGOs; 3) Management process perspective, most of the factories had plans and projects concerning pollution reduction with sufficient budget, personnel and equipment but the proportion of factories conducting monitoring was not high; 4) Learning and development perspective, most of VOCs target factories continuously
\end{abstract}


developed the ability of their personnel but the proportion was low for the $\mathrm{SO}_{2}$, and $\mathrm{NO}_{\mathrm{x}}$ target factories. This study then suggests ways to improve the Rayong's air pollution management in 4 perspectives according to the $\mathrm{BSC}$ technique.

Keywords: air pollution management, VOCs, $\mathrm{SO}_{2}, \mathrm{NO}_{x}$, industrial area, balanced Scorecard.

\section{Introduction}

Rayong Province is the largest industrial area in Thailand, located about 200 $\mathrm{kms}$, east of Bangkok. This province has been designated by the government to be an industrial area since 1981 under the "Eastern Seaboard Scheme" following the discovery of natural gas in Thai Gulf. Petrochemical and related productions are key industries in the area. Maab Ta Put Industrial Estate is the first industrial estate established in the province in 1982 run by the government's Industrial Estate of Thailand. The industries in Rayong Province have expanded rapidly. At present, there are about 1,700 factories in Rayong Province with the investment of around 27,170,000 mill.US\$, of which 400 large factories are located in 8 industrial estates (Figure 1). Rayong province contributes around $14 \%$ of Thailand's GDP with the highest GDP per capita among all provinces in Thailand [1].

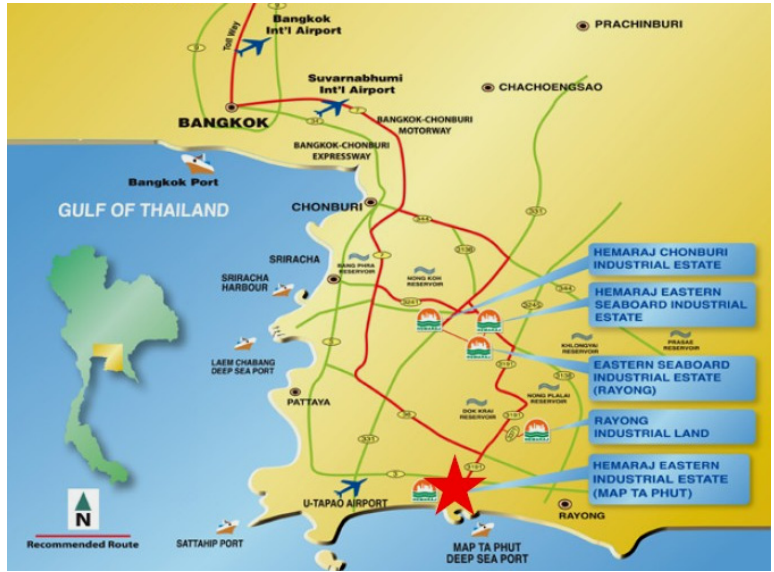

Figure 1: Location of Rayong province and its main industrial estates.

In line with this appreciable contribution to the country's economic development, Rayong Province has been facing several severe environmental problems which have imposed serious impacts on health and quality of life of the local people. Some examples of the problems are:

1) In 2000-2003, there were serious olfactory problems from petrochemical and refinery plants.

2) In 2005 , there was serious shortage of water supply leading to conflict between the factories and the local communities. 
3) In 2007, there had been a very strong and continuing movement of local people and NGOs requesting the Rayong's industrial area to be a pollution control zone. Eventually, the government declared the industrial area as the pollution control zone in 2009.

The most important pollution in Rayong's industrial area is air pollution and the major air pollutants are VOCs, $\mathrm{SO}_{2}$, and $\mathrm{SO}_{\mathrm{x}}$. More than 40 types of VOCs found, of which 20 VOCs are carcinogent. The most concerned VOCs in the area are benzene, butadiene and 1,2-dichloroethene [2].

According to the impact from air pollution and the other pollutions in the Rayong's industrial area the government by the Department of Industrial Works, the Industrial Estate of Thailand and the Pollution Control Department has been trying to mitigate the problems through several measures including implementation of the Pollution Reduction in Rayong Province Action Plan, 2007-2011, in which the factories were requested for concrete co-operation. Nevertheless, the problems still exists as seen from occasional protests from the local people and NGOs. Sometimes they were very serious as the protesters blocked the entrances of the industrial estates. Hence, it is very useful to investigate achievements and obstacles of these measures which can lead to suggestions to improve the management. As a consequence, the objectives of this study are: 1) to study air pollution situation in the Rayong's industrial area; 2) to examine the management of air pollution in Rayong's industrial area; and 3) to suggest ways for improvement of air pollution management in the area.

\section{Methodology}

\subsection{Methods for data collecting}

This study employed both primary and secondary data collecting methods. For the primary data collection, questionnaires were distributed to 2 target groups. The first target group were 31 large factories having potential of emitting high volume of VOCs, and the second group were 25 large factories which were major sources of $\mathrm{SO}_{2}$ and $\mathrm{NO}_{\mathrm{x}}$ emissions.

In addition, secondary data were gathered from relevant reports and statistics on air pollution and health of the Department of Pollution Control, Maab Ta Put Industrial Estate Office, Rayong Provincial Public Health Office, etc.

\subsection{Methods for data analysis}

The Balanced Scorecard (BSC) technique was employed for the analysis of the factories' air pollution management. The BSC technique which was initiated by Kaplan and Norton [3] was design for evaluating performances of business firms and for creating strategies and activities to sustainably improve firms' performances. It has been recently adopted for management of public organizations including those in Thailand. This study saw the advantages of this technique and therefore adopted it for the data analysis and suggestions with some modifications to make it suit the environmental management performances 
of target factories. Hence, the four original BSC perspectives which are Financial, Customer, Internal Process and Learning and Growth, were modified to be Effectiveness, Stakeholder, Management Process and Learning and Development perspectives.

\section{Air pollution and health situations in Rayong's industrial area}

The air pollution problem in Rayong has been of very much concern to local people, central government agencies, regional government offices and local authorities. The most concerned air pollutants are Volatile Organic Compounds (VOCs) due to a large number of petrochemical factories concentrated in Rayong's industrial area. Other air pollutants which have been of concern are $\mathrm{SO}_{2}, \mathrm{NO}_{\mathrm{x}}$, and particulate matters. These pollutants are believed to pose serious impact on health of local people living close to the industrial area.

\subsection{Volatile organic compounds (VOCs)}

Results of the monitoring of VOCs from 9 stations around the Rayong industrial area from 2007-2010 showed that there were 3 types of VOCs - benzene, 1,3 butadiene, and 1,2 dichloroethane - which their average 1 year volumes exceeded the Thai national standards [4]. Another concerned VOC was dichloromethane which its volume tended to increase during the last 4 years. The data also indicated that the stations where the VOCs volumes exceeded the standards mainly located close to the dense industrial areas of Maab Ta Put Industrial Estate and IRPC Industrial Estate. Figures 2 to 4 show the results of air quality monitoring at the 9 stations.

\subsection{Other air pollutants}

The results of air quality monitoring in Rayong's Pollution Control Area from 2004-2010 revealed that the 24-hour maximum volumes of $\mathrm{PM}_{10}$

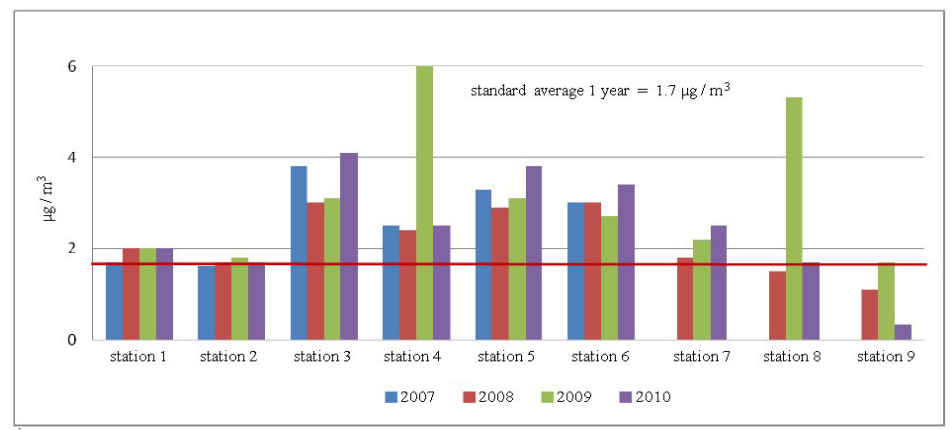

Figure 2: Benzene volumes in Rayong, 2007-2010. 


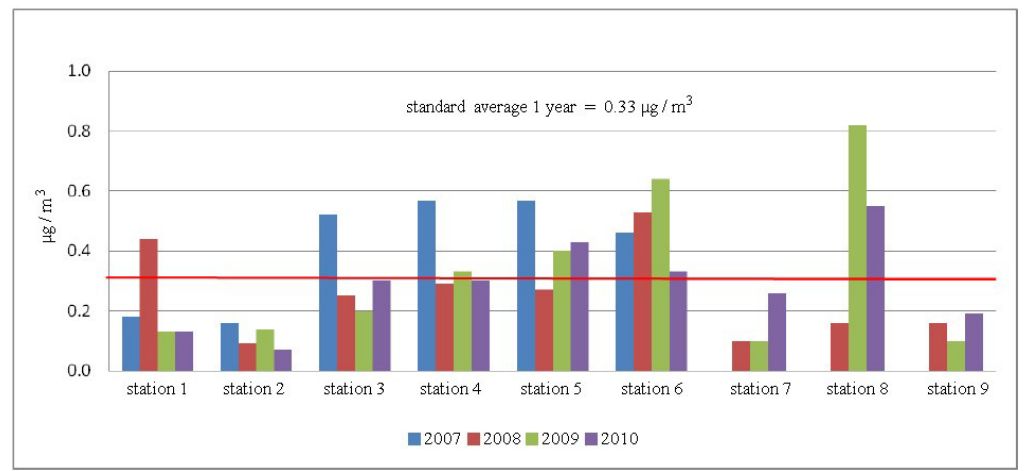

Figure 3: $\quad$ 1,3 butadiene volumes in Rayong, 2007-2010.

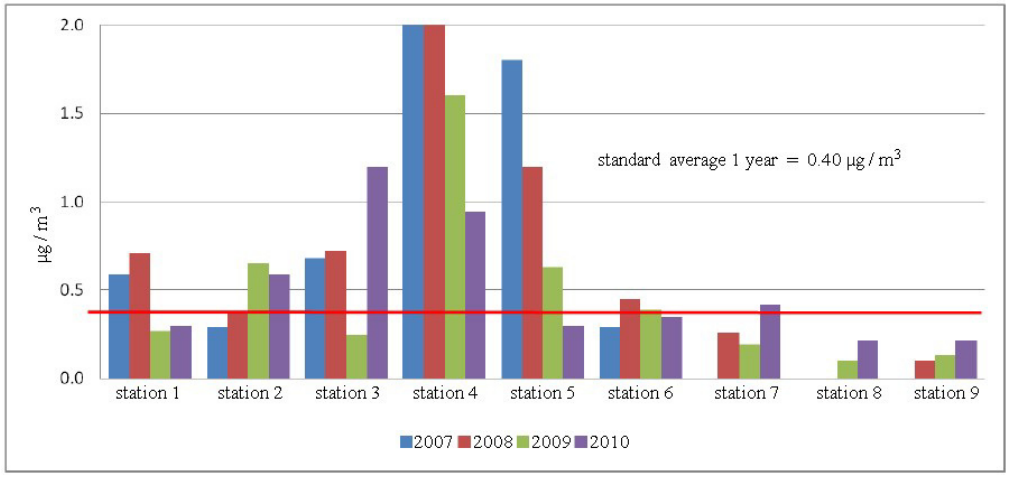

Figure 4: 1,2 dichloroethene volumes in Rayong, 2007-2010.

exceeded the standards from 2004 to 2008. On the other hand, maximum volumes of Ozone were within the Thai national standard from 2004 to 2006 but the volumes exceeded the standard from 2007 to 2010. In addition, the maximum volumes of $\mathrm{SO}_{2}$, and $\mathrm{NO}_{\mathrm{x}}$ were within the Thai national standards for these 7 years (Table 1).

\subsection{Health situation}

Regarding health of Rayong people, the Department of Pollution Control (2007: website) reported that the highest number of people came to get checked about respiratory diseases from the external patient sections of hospitals and other health service organizations. In addition, the ratio of people suffered from respiratory diseases in Rayong was higher than that of the country. Worse, the trend in Rayong is increasing while the trend of the countrywide is decreasing. In terms of deaths from cancer, ratio of the deaths from cancer in Rayong's industrial area is higher than that of overall Rayong and the country, particularly lung cancer. However, there is no specific study to confirm the relationship between these sicknesses and deaths and pollution in Rayong's industrial area. 


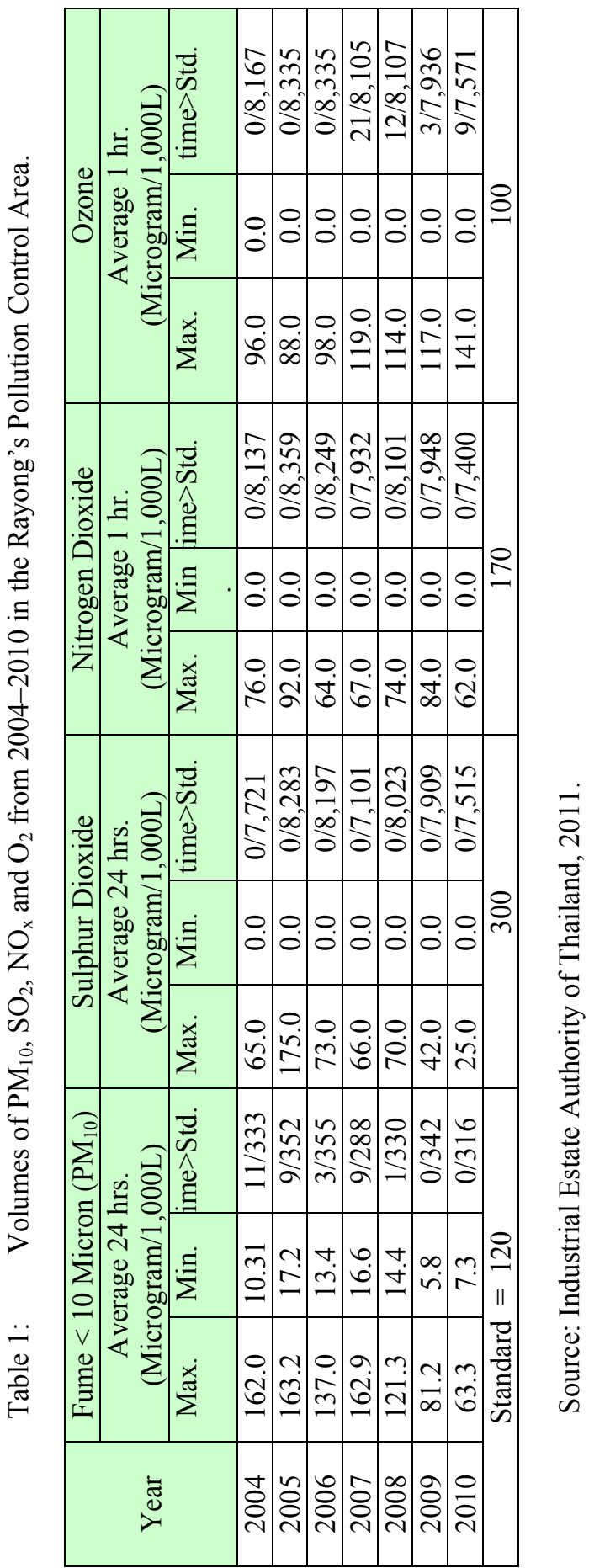




\section{Factories' performances as of the 4 perspectives of BSC}

\subsection{Effectiveness perspective}

\subsubsection{VOCs emissions}

The study found that $51.6 \%$ of target factories had 1 type of VOCs, $29 \%$ had 2 VOCs, and $6.5 \%$ had 4 VOCs, where $29 \%$ of the factories had benzene, $30.8 \%$ had other VOCs such as Hexane, Ethylene, Propylene, Butane, Styrene, Methanol, Toluene, Hydro Carbon, LPG, etc., 10.4\% had 1,3 Butadiene, 1,2 Dichloroethane or Vinyl Chloride, and only 1 factory had Dichloromethane. Regarding their effectiveness in VOCs controlling, the study found that:

1) $87.1 \%$ of the factories were able to completely control the VOCs leaking points, where $9.7 \%$ did not conduct any measure to control the leaking points;

2) $93.5 \%$ of the factories monitored and control the VOCs leaking points continuously where $6.5 \%$ had no monitoring system;

3) $54.8 \%$ of the factories finished establishing VOCs inventories, $41.9 \%$ were in the process, where $3.2 \%$ ( 1 factory) did not start the work.

\subsection{2 $\mathrm{SO}_{2}$ and $\mathrm{NO}_{\mathrm{x}}$ emissions}

About $40 \%$ of the target factories emitted both $\mathrm{SO}_{2}$ and $\mathrm{NO}_{\mathrm{x}}, 52 \%$ emitted only $\mathrm{NO}_{x}$, and only $8 \%$ emitted only $\mathrm{SO}_{2}$. The study on the effectiveness perspective found that after implementing $\mathrm{SO}_{2}$ and $\mathrm{NO}_{x}$ reduction plans and projects about $84 \%$ of the factories had lower emissions of $\mathrm{SO}_{2}$ and $\mathrm{NO}_{\mathrm{x}}$, where:

1) average $\mathrm{SO}_{2}$ emission before implementing the plans and projects was $1,186.42 \mathrm{mg} / \mathrm{m}^{3}$ with the maximum volume of $18,000 \mathrm{mg} / \mathrm{m}^{3}$. After the implementation the average was $511.57 \mathrm{mg} / \mathrm{m}^{3}$ and the maximum was $12,000 \mathrm{mg} / \mathrm{m}^{3}$;

2) average $\mathrm{NO}_{\mathrm{x}}$ emission before implementing the plans and projects was $1029.91 \mathrm{mg} / \mathrm{m}^{3}$ with the maximum volume of $19,000 \mathrm{mg} / \mathrm{m}^{3}$. After the implementation the average was $510.14 \mathrm{mg} / \mathrm{m}^{3}$ and the maximum was 8,000 $\mathrm{mg} / \mathrm{m}^{3}$.

\subsection{Stakeholder perspective}

\subsubsection{VOCs}

For supports and co-operations from relevant agencies and groups, $90.3 \%$ of the factories received supports and co-operations in VOCs controlling from central government agencies such as Pollution Control Department, Department of Industrial Works, $87.1 \%$ received from other units within their factories, $80.6 \%$ from surrounding communities, and $64.5 \%$ from other factories.

On the other hand, $93.5 \%$ of the factories did not get support or co-operation from NGOs, $71 \%$ did not get from the Province or District, $61.3 \%$ did not get from local authorities, and $58.1 \%$ did not get from education institutes or academics. 


\subsection{2 $\mathrm{SO}_{2}$ and $\mathrm{NO}_{\mathrm{x}}$}

Regarding supports and co-operations from relevant agencies and groups, 100\% of the factories received supports and co-operations in $\mathrm{SO}_{2}$ and $\mathrm{NO}_{\mathrm{x}}$ controlling from the Industrial Estate Office and surrounding communities, 96\% received from other units within their factories, 92\% received from central government agencies such as Pollution Control Department, Department of Industrial Works, $76 \%$ received from the Province and District, and 64\% received from other factories.

On the other hand, $92 \%$ of the factories did not get support or co-operation from NGOs, $71 \%$ did not get from province or district, $60 \%$ did not get from local authorities, and $56 \%$ did not get from education institutes or academics.

\subsection{Management process perspective}

This perspective considers the factories' process in air pollution management particularly in controlling of $\mathrm{VOCs}, \mathrm{SO}_{2}$ and $\mathrm{NO}_{\mathrm{x}}$, such as establishing policy, making plans and projects, allocating sufficient budget, personnel, and equipment, and adopting technology.

\subsubsection{VOCs}

About $67 \%$ of the factories established policies for reduction of VOCs emissions, $83.9 \%$ had plans and projects, $90.3 \%$ had sufficient budget in implementing the policy, plans and projects, $80.6 \%$ had enough personnel, $67.7 \%$ monitored $\mathrm{SO}_{2}$ and $\mathrm{NO}_{x}$ emissions continuously, $67.7 \%$ had enough equipment for VOCs monitoring, and 77.4\% employed technology for monitoring and controlling of VOCs leaking points.

Technologies employed were using dual mechanical seal pumps or seal-less pump, using closed loop system in sampling connections, installing blinds, caps or plugs at open-ended pipes, using double rim seals for floating roof tank, installing incineration system, using activated carbon for VOCs absorbing, installing scrubber, etc.

\subsection{2 $\mathrm{SO}_{2}$ and $\mathrm{NO}_{\mathrm{x}}$}

About $64 \%$ of the factories established policies for reduction of $\mathrm{SO}_{2}$ and $\mathrm{NO}_{\mathrm{x}}$ emissions, $76 \%$ had plans and projects, $96 \%$ allocated sufficient budget in implementing the policy, plans and projects, $92 \%$ had enough personnel, $96 \%$ monitored $\mathrm{SO}_{2}$ and $\mathrm{NO}_{x}$ emissions continuously, and $80 \%$ employed modern technology for reducing and controlling of $\mathrm{SO}_{2}$ and $\mathrm{NO}_{\mathrm{x}}$ emissions, $88 \%$ monitored and evaluated progress of the plans and projects continuously.

Technologies used were, for example: low $\mathrm{NO}_{\mathrm{x}}$ burner, wet electrostatic precipitator, steam injection, steam de- $\mathrm{NO}_{\mathrm{x}}$, circulating fluidized bed boiler, bag filter single cyclone, sea water desulphurization, as well as using alternative fuels. 


\subsection{Learning and development perspective}

\subsubsection{VOCs}

About $77 \%$ of the factories provides trainings for their personnel responsible for VOCs controlling plans and projects, only 32.3\% had learned new knowledge from the operation of VOCs controlling such as making VOCs emission inventory, using modern technology in monitoring of VOCs leaking points both fugitive and stationary sources, methods for calculation of fugitive VOCs emissions, methods in selecting equipment for calculation of VOCs emission. In addition, only $32.3 \%$ of the factories extended their knowledge learned to their related operations such as making VOCs emission inventory, methods for monitoring of VOCs leaking points, and methods for reducing and controlling of VOCs emissions.

\subsection{2 $\mathrm{SO}_{2}$ and $\mathrm{NO}_{\mathrm{x}}$}

The study found that only $28 \%$ of the factories provides trainings for their personnel responsible for $\mathrm{SO}_{2}$ and $\mathrm{NO}_{\mathrm{x}}$ controlling and those working in production section, only $12 \%$ had learned new knowledge from the operation of $\mathrm{SO}_{2}$ and $\mathrm{NO}_{\mathrm{x}}$ controlling such as low $\mathrm{NO}_{\mathrm{x}}$ burner, $\mathrm{NO}_{\mathrm{x}}$ controlling in production process, using alternative fuel such as natural gas. In addition, $12 \%$ of the factories extended their knowledge to the related operations such as conducting studies to change to alternative fuels, controlling $\mathrm{NO}_{\mathrm{x}}$ volume continuously by controlling machine and equipment, etc.

\section{Conclusions and discussions}

This study revealed that, within the evaluation framework of BSC, the target factories performed quite well in management of air pollution problems both VOCs and $\mathrm{SO}_{2}$ and $\mathrm{NO}_{\mathrm{x}}$. However, there are weak points in some perspectives as discussed below:

Effectiveness perspective: Most factories of the VOCs target group were able to control their VOCs leaking points, and over $80 \%$ of factories in the $\mathrm{SO}_{2}$ and $\mathrm{NO}_{\mathrm{x}}$ target group had significantly lower $\mathrm{SO}_{2}$ and $\mathrm{NO}_{\mathrm{x}}$ emissions. Nevertheless, the results from several monitoring stations around the Rayong's industrial area showed that the volumes of 3 VOCs - benzene, 1,2 butadiene and 1,2 dichloroethene-substantially exceeded the standards. This indicates the need for thorough analysis of VOCs emission sources and more effective measures for reduction and control of VOCs.

Stakeholder perspective: Most target factories received good supports and cooperations from central government agencies, other factories, other units within their factories and local communities. On the other hand, they received much less co-operation from NGOs, local authorities, and education institutes and academics. The study results match the fact that most of the movements or protests against factories or industry in Rayong area are led by NGOs both local and outside. For local authorities, they do not have much role to play with the industry. They mainly focus on common environmental problems such as 
community wastes and wastewater. Another reason can be lacking of technical knowledge to deal with air pollution problems. In addition, the gaps with education institutes and academics can be attributable to an absence of higher education institute in Rayong province and loose relationship between the industry and academics.

Management process perspective: The majority of the target factories had plans and project for reduction and controlling of VOCs, and $\mathrm{SO}_{2}$ and $\mathrm{NO}_{\mathrm{x}}$, though much fewer factories established the policies. This could be a weak point for an effective environmental management as emphasized by, for example, the Environmental Management System Standard (ISO 14001) that the policy represents commitment of firm's top management [5]. The majority of the target factories also had sufficient budget, personnel, equipment, and employed modern technologies to reduce and control the emissions. However, the proportion of factories having conducted VOCs emissions monitoring continuously was not that high.

Learning and development perspective: Although the majority of VOCs target factories provided trainings for their personnel responsible for VOCs controlling, very low number of $\mathrm{SO}_{2}$ and $\mathrm{NO}_{\mathrm{x}}$ target factories provided trainings for their staff. This could be because technologies utilized for reducing and controlling of VOCs emissions are quite new to the personnel compared with those for $\mathrm{SO}_{2}$ and $\mathrm{NO}_{\mathrm{x}}$. The other concerns are about level of learning from the implementation of VOCs, $\mathrm{SO}_{2}$ and $\mathrm{NO}_{\mathrm{x}}$ controlling projects and measures and the extension of the knowledge which were quite low in both target groups. This learning and development perspective is very important as it is a foundation for a sustainable success in any management system including the Rayong's air pollution management in this case.

\section{Recommendations}

According to the strengths and weaknesses of air pollution management in Rayong's industrial area found from this study, recommendations for improving the performances of the target factories and for overall management are as follows:

1) Effectiveness perspective: To make the air pollution management in Rayong's industrial area more effective, the government has to stipulate specific air pollution reduction and control policy, particularly on VOCs, covering all emission sources, set up an agency for monitoring and controlling the operation, and issue relevant legislations;

2) Stakeholder perspective: The target factories should build better understandings with NGOs and local authorities by sharing information and involve them in air pollution management process. In addition, the factories should seek more supports and co-operations from higher education institutes and academics outside Rayong province. Providing fund for researches on appropriate air pollution control technologies or requesting for conducting air quality monitoring would be effective approaches to get closer link with the academics. 
3) Management process perspective: Top management of each target factory should formulate specific policy on air pollution management to indicate a prominent direction for all staff which can lead to concrete operation. Furthermore, target factories should conduct monitoring and evaluation system continuously;

4) Learning and development perspective: the factories and relevant agencies should set up a learning and development center for study, research and training on air pollution control. The priority groups should be factories' personnel responsible for $\mathrm{VOCs}, \mathrm{SO}_{2}$ and $\mathrm{NO}_{\mathrm{x}}$ control. Furthermore, trainings and information should be provided for NGOs, local government officers and local communities.

\section{References}

[1] Rayong Provincial Industry Office, Information of Industry in Rayong Province, http://www.industry.go.th/ops/pio/rayong/Page/home.aspx, 2010.

[2] Pollution Control Department, Pollution Mitigation in Maab Ta Put Area, www.pcd.go.th/info_serv/pol_maptapootst.html_14k, 2009.

[3] Kaplan R.S. and Norton D.P., The Balanced Scorecard: Translating Strategy into Action, Harvard Business School Press: Massachusetts, 1996.

[4] Industrial Estate Authority of Thailand, Final Report of Strategic Environmental Framework towards Eco-Industrial Town: A Case Study of Maab Ta Put Area, 2011.

[5] Poboon, C., ISO 14001: Environmental Management System, Thipnetr Printing: Bangkok, pp. 7-1 to 7-2, 2009. 